\title{
Virtual supervision during the COVID-19 pandemic
}

Victor Rendon, DO, MPA

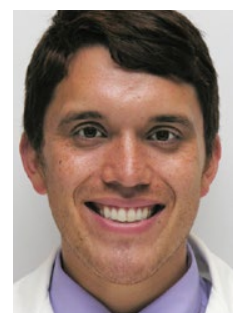

Dr. Rendon is a PGY-2 Psychiatry Resident, ChristianaCare Health System, Wilmington, Delaware.

\section{Disclosure}

The author reports no financial relationships with any companies whose products are mentioned in this article, or with manufacturers of competing products.

doi: 10.12788/cp.0095

\section{$f$}

Discuss this article at www.facebook.com/ MDedgePsychiatry
$\mathrm{T}$ he coronavirus disease 2019 (COVID19) pandemic has fundamentally changed our way of life. It has affected everything from how we go to the grocery store, attend school, worship, and spend time with our loved ones. As vaccinations are becoming available, there's hope for a time when we can all enjoy a mask-free life again. Despite this, many of us are beginning to sense that the precautions and technology employed in response to COVID-19, and some of the lessons learned as a result, are likely to stay in place long after the virus has been controlled.

Working remotely through audio and visual synchronous communication is now becoming the norm throughout the American workplace and educational system. Hospitals and graduate medical education programs are not exempt from this trend. For at least the foreseeable future, gone are the days of "unsocially distanced" bedside rounds in which 5 to 10 residents and medical students gather around with their attending as a case is presented in front of an agreeable patient.

\section{My experience with 'virtual' supervision}

Telemedicine has played a key role in the practice of health care during this pandemic, but little has been written about "telesupervision" of residents in the hospital setting. An unprecedented virtual approach to supervising emergency medicine residents was trialed at the University of Alabama a few months prior to my experience with it. This was found to be quite effective and well-received by all involved parties. ${ }^{1}$

I am a PGY-2 psychiatry resident at ChristianaCare, a large multisite hospital system with more than 1,200 beds that serves the health care needs of Delaware and the surrounding areas. I recently had a novel educational experience working on a busy addiction medicine consult service. On the first day of this rotation, I met with my attending, Dr. Terry Horton, to discuss how the month would proceed. Together we developed a strategy for him to supervise me virtually.

Our arrangement was efficient and simple: I began each day by donning my surgical mask and protective eyewear and reviewing patients that had been placed on the consult list. Dr. Horton and I would have a conversation via telephone early in the morning to discuss the tasks that needed to be completed for the day. I would see and evaluate patients in the standard face-to-face way. After developing a treatment strategy, I contacted Dr. Horton on the phone, presented the patient, shared my plan, and gained information from his experienced perspective.

Then we saw the patient "together." We used an iPad and Microsoft Teams video conferencing software. The information shared

LET YOUR VOICE BE HEARD

CURRENT Psychiatry invites psychiatry residents to share their views on professional or clinical topics for publication in Residents' Voices. E-mail jbauer@mdedge.com for author guidelines. 
was protected using Microsoft Teams accounts, which were secured with profiles created by our institutional accounts. The iPad was placed on a rolling tripod, and the patient was able to converse with Dr. Horton as though he was physically in the room. I was there to facilitate the call, address any technical issues, and conduct any aspects of a physical exam that could only be done in person. After discussing any other changes to

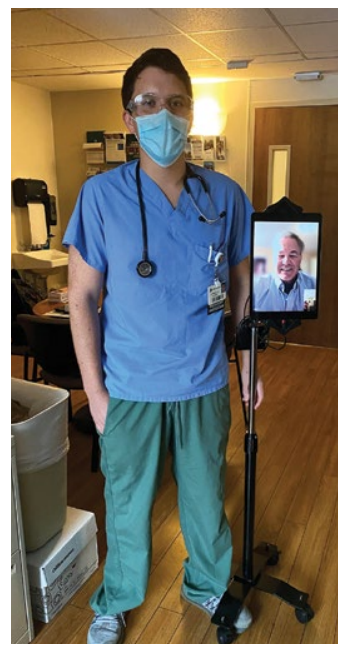

well as for his outpatient practice. He used to spend a great deal of time traveling between different sites. With increasing need for his expertise, this model became increasingly difficult to practice. Our new model of attending supervision is welcomed in some settings because the attending can virtually be in multiple places at the same time.

For me, this experience has been positive. For a physician in training, virtual rounding the treatment plan, I placed all medication orders, shared relevant details with nursing staff and other clinicians, wrote my progress note, and rolled my "attending on a stick" over to the next patient. Meanwhile, Dr. Horton was free to respond to pages or any other issues while I worked.

This description of my workflow is not very different from life before the virus. Based on informal feedback gathered from patients, the experience was overall positive. A physician is present; patients feel well cared for, and they look forward to visits and a virtual presence. This virtual approach not only spared unnecessary physical contact, reducing the risk of COVID-19 exposure, it also promoted efficiency.

Fortunately, our hospital is surrounded by a solid telecommunications infrastructure. This experience would be limited in more remote areas of the country. At times, sound quality was an issue, which can be especially problematic for certain patients.

Certain psychosocial implications of the pandemic, including (but not limited to) social isolation and financial hardship, are often associated with increased substance use, and early data support the hypothesis that substance use has increased during this period. ${ }^{2}$ Delaware seems to be included in the national trend. As such, our alreadybusy service is being stretched even further. Dr. Horton receives calls and is providing critical recommendations continuously throughout the day for multiple hospitals as can provide a critical balance of autonomy and support. I felt free on the rotation to make my own decisions, but I also did not feel like I was left to care for complicated cases on my own. Furthermore, my education did not suffer. In actuality, the experience enabled me to excel in my training. An attending physician was there for the important steps of plan formulation, but solo problem-solving opportunities were more readily available without his physical presence.

Aside from the medical lessons learned, I believe the participation has given me a glimpse of the future of medical training, health care delivery, and life in the increasingly digital post-COVID-19 world.

Hopefully, my experience will be helpful for other hospital systems as they continue to provide high-quality care to patients and education/training to their resident physicians in the face of the pandemic and the changing landscape of health care.

\section{Acknowledgment}

The author thanks Mustafa Mufti, MD, ChristianaCare Psychiatry Residency Program Director; Rachel Bronsther, MD, ChristianaCare Psychiatry Residency Associate Program Director; and Terry Horton, MD, ChristianaCare Addiction Medicine, for their assistance with this article.

\section{References}

1. Schrading WA, Pigott D, Thompson L. Virtual remote attending supervision in an academic emergency department during the COVID-19 pandemic. AEM Educ Train. 2020;4(3):266-269.

2. Czeisler MÉ, Lane RI, Petrosky E, et al. Mental health, substance use, and suicidal ideation during the COVID-19 pandemic - United States, June 24-30, 2020. MMWR Morb Mortal Wkly Rep. 2020;69(32):1049-1057.

\section{Clinical Point}

For a physician in training, virtual rounding can provide a critical balance of autonomy and support 